Natural Hazards and Earth System Sciences (2002) 2: 227-238

(C) European Geosciences Union 2002

Natural Hazards
and Earth
System Sciences

\title{
The EU CADZIE database for extreme and deflected snow avalanches
}

\author{
U. Domaas ${ }^{1}$, C. B. Harbitz ${ }^{1}$, and H. Bakkehøi ${ }^{1}$ \\ ${ }^{1}$ Norwegian Geotechnical Institute, P.O. Box 3930, Ullevål stadion, N-0806 Oslo, Norway
}

Received: 20 September 2001 - Revised: 19 December 2001 - Accepted: 16 January 2002

\begin{abstract}
The EU programme CADZIE (Catastrophic Avalanches: Defence Structures and Zoning in Europe), was established after the catastrophic 1999 avalanche winter in Europe. The overall objective of the programme is improved snow avalanche risk management by: (1) improved avalanche hazard zoning by computational models; and (2) improved understanding of the interaction between defence structures and avalanches.

One contribution to meet the objectives is a database of well-documented extreme or deflected avalanche events in the six countries of the partners of the programme. The database contains observational, topographical and meteorological snow avalanche data with reliability, as well as references, copyrights, etc., all in a convenient framework based on common formats.

The structure, contents, and potential use of the database are described. Example calculations of extreme and deflected events made by the NGI user interface "SKRED", for practical use of avalanche computational models, present applications of the database. Finally, further development of the database and of the computational models to meet the future needs in avalanche hazard zoning is proposed.
\end{abstract}

\section{Introduction}

Increased human activity and expensive infrastructure in mountain regions, combined with a possible increase in avalanche activity and a reduced social acceptance of risk, have caused a growing demand for improved mitigative measures. This was clearly illustrated by the catastrophic avalanche accidents in Austria, Switzerland and France in January and February 1999.

Active avalanche control (controlled artificial release by explosives, etc.) is often hardly feasible in build-up areas. Hence, passive avalanche control, such as hazard zoning and defence structures, should be considered. Efficient zoning

Correspondence to: U. Domaas (ud@ ngi.no) and dam design critically depend on knowledge of extreme avalanche events. Information on extreme events in terms of release conditions, and the extension and effect of possible defence structures, constitutes a sound means for the desired improvement of these issues. Experience from one event or region can most often be applied in aerial planning and dam design in other areas with little or no historical information.

Obviously, extreme events are rare. Likewise, very few naturally deflected avalanches have been studied in detail. Only a few deflecting and catching dams are built in each country that faces avalanche problems and even fewer dams have been struck by avalanches. Hence, experience on extreme and deflected avalanches is still scarce in each country. To obtain as much understanding of the phenomenon as possible, the requested information should, therefore, not be restricted to a few accidental events in central Europe in 1999. To gather "enough" information, a joint effort between professional avalanche institutions, as well as open and easy exchange of information is essential.

The EU CADZIE programme for joint European effort on improved hazard zoning and defence measures is described in Sect. 2. One important deliverable to this programme is the EU CADZIE database on extreme and deflected snow avalanches presented in Sect. 3. Finally, in Sect. 4, a few calculational examples by simple models for practical use illustrate some potential applications and how increased insight can be gained from the database.

\section{The EU programme CADZIE 2000-2003}

The EU programme CADZIE (Catastrophic Avalanches: Defence Structures and Zoning in Europe) was established after the 1999 catastrophic avalanche winter in Europe. The project is funded by the fifth European Research Framework Programme and conducted by Cemagref ETNA, Grenoble, France, and comprises altogether ten avalanche research institutions from six European coun- 
tries. Additional information is found on the internet address: http://cadzie.grenoble.cemagref.fr.

The overall objective of the programme is improved snow avalanche risk management by improved avalanche hazard zoning and improved understanding of the interaction between defence structures and avalanches. Both aspects require improved understanding of avalanche release conditions and dynamics, which among other enhanced factors, will help to deduce the criteria for extreme events and the physical laws governing momentum and energy dissipation during avalanche/defence structure interaction. This, in turn, constitutes the basis for a new generation of numerical models.

The project is split into five work packages on: (1) zoning (hazard, probability, risk, model calibration); (2) avalanche/defence structure interaction of powder snow avalanches; (3) avalanche/defence structure interaction and deflection of dense snow avalanches; (4) field data and database; and finally, (5) transfer to end-users (standardised zoning tools, courses, and handbooks for engineers, consultants and planners). This paper can be considered a contribution to the last two work packages.

The EU CADZIE programme is a continuation of the EU SAME (avalanche mapping, model validation and warning systems) programme 1995-1998, funded by the fourth European Research Framework Programme and also conducted by Cemagref ETNA. Additional information is found on the internet address: http://same.grenoble.cemagref.fr/private/cdrom/home.htm, where access can also be gained to the deliverables (also available on the CD-ROM "EUR 19069 - Avalanche mapping model validation and warning systems"). In summation, the deliverables of SAME are reports on existing maps and databases, computational models, test sites, and detection systems, as well as a common user interface for model integration, a model comparison that identified current status and research needs, and finally, a draft proposal for joint European full-scale avalanche experiments. The latter discusses in detail modellers' needs for experimental and observational data and how to obtain them.

\section{The EU CADZIE database}

\subsection{Objectives}

A database on extreme and deflected snow avalanches with data carefully selected to cover the needs of avalanche practitioners, researchers and modellers can be used to:

- bring about and ease exchange of empirical knowledge;

- increase the understanding of meteorological factors that originate release of extreme events;

- increase the understanding of the dynamics of extreme and deflected avalanches, and thereby help to deduce the physical laws governing momentum and energy dissipation during avalanche/defence structure interaction;
- improve procedures and tools for avalanche hazard zoning and design of defence structures by:

- further use, interpretation and development of statistical models;

- verification, validation, and further development of numerical models for simulation of avalanche motion and avalanche/defence structure interaction;

- physically define the range of model parameter values that allow the models to properly back-calculate certain events;

- identify the uncertainty of the computational models;

- increase the understanding of scaling effects (where the database contains data on events of various scales).

\subsection{Limitations on use}

The limitations are mainly related to the topographical data, normally provided by the map authorities in each country. Most of the digital maps and terrain models are provided only for research work performed by the CADZIE partners, and in some cases, only for work within the project period. In addition, the owner (given in the database) should be contacted in each case. To ensure that these orders are kept, the database is presently password restricted. Hopefully an agreement can be reached between the project partners and the map owners such that the database can be more open, and also that it can be used, maintained and enlarged after the project is concluded.

\subsection{Structure and formats}

To ensure easy access, the EU CADZIE database is activated from the internet front-page http://cadzie.ngi.no (password restricted), Fig. 1a. To simplify the matter, the frontpage presents a list of the included avalanche events in each participating country and a link to the avalanche database overview, Fig. 1b. To ensure readability, the latter is presently made in standard MS Excel format. Later on it will be converted to a MS Access file to enable inquiries and extraction.

For each avalanche event on the front-page there is a subpage with links to pictures and data files of appropriate common formats containing the information listed below, Fig. 2a. The files are given names according to a certain standard, and the formats have been selected based on a questionnaire distributed to all partners.

Special attention has been paid to formats used for digital maps and terrain. The Geographical Information System (GIS) tools used by the participants are ArcView/Info, GeoMedia, and Auto-Cad Map. Also used are the numerical tools Grass and Surfer for construction and presentation of digital terrain. All five "terrain tools" apply different input/output formats. Finally, the EU CADZIE database contains digital vectorised maps for ArcView/Info (.e00 or .shp 
a)

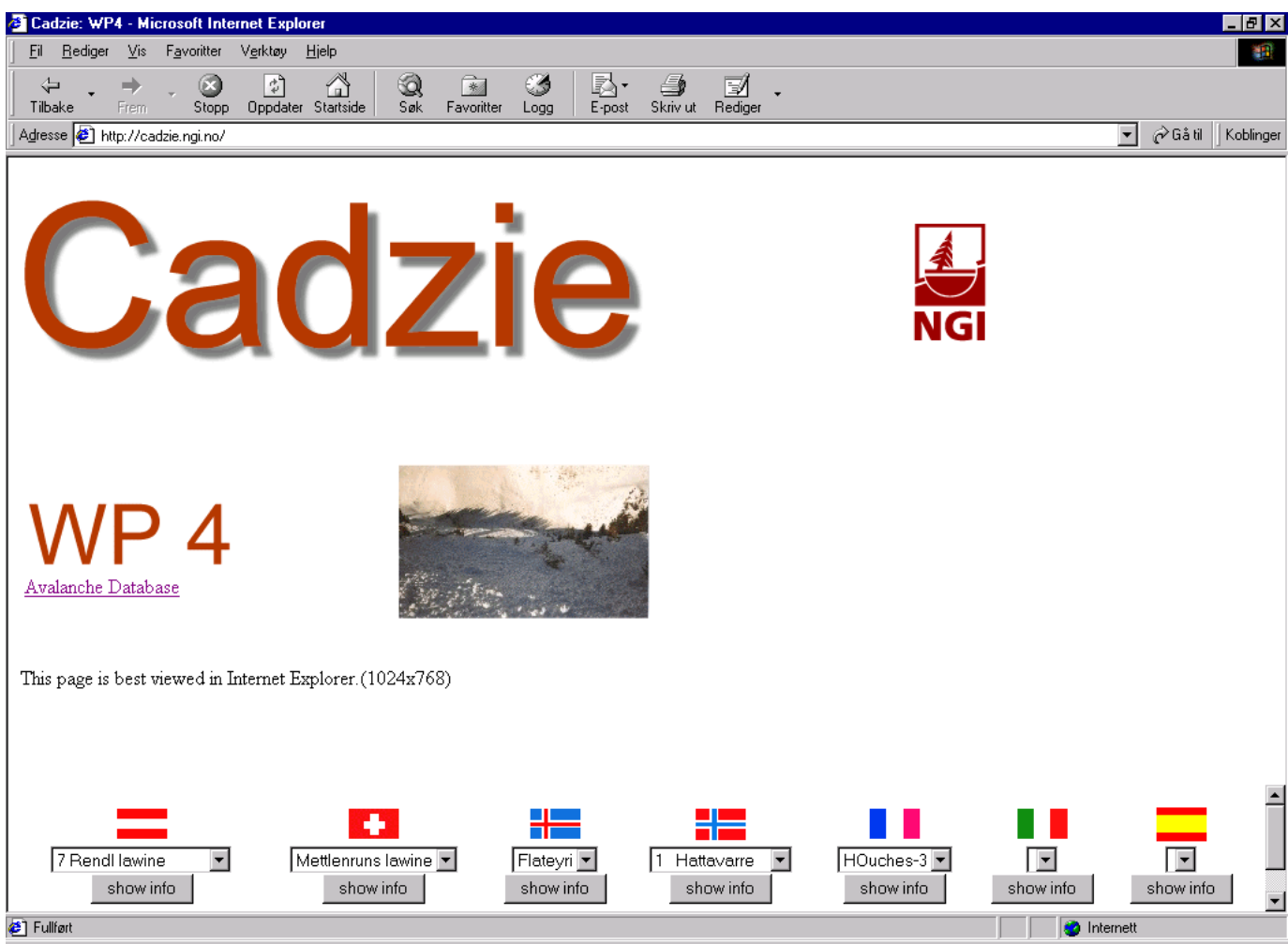

b)

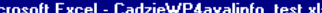

|\$3 Eil Rediger vis Settinn Format Verktøy Data Vindu Hielp

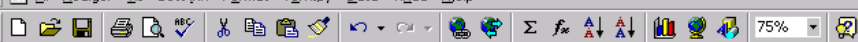

\begin{tabular}{|c|c|c|c|c|c|c|c|c|c|}
\hline \multicolumn{2}{|c|}{ Arial } & \multirow{2}{*}{\multicolumn{2}{|c|}{$\begin{aligned} & =\mathbf{F} K \underline{\mathbf{U}} \\
\nabla & =\text { February }\end{aligned}$}} & \multicolumn{6}{|c|}{ 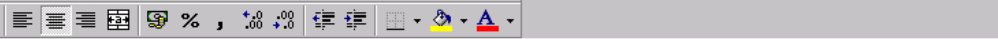 } \\
\hline \multicolumn{2}{|r|}{ M30 } & & & & & & & & \\
\hline & A & $B$ & C & $D$ & $E$ & $F$ & G & H & \\
\hline$\frac{1}{2}$ & $\begin{array}{l}\text { Avalanche ID } \\
\text { Rendl }\end{array}$ & $\begin{array}{r}\text { Country } \\
\text { Austria }\end{array}$ & $\frac{\text { Region }}{\text { St Anton }}$ & \begin{tabular}{|l} 
Municipality \\
Arlbergitirol
\end{tabular} & $\frac{\text { Local name }}{\text { St Anton }}$ & Map ID & \begin{tabular}{|l} 
UTM ref. (Zone $\cdot$..,.) \\
GAUSS-KRŪGER M28
\end{tabular} & $\begin{array}{l}\text { Extreme or Deflected aval. } \\
\text { Estreme }\end{array}$ & Deflected aval ( $\mathrm{N}:-$ \\
\hline 3 & Biendl & & & & & & & & \\
\hline 5 & Gentiesskogel & Austria & Galtüit & Paznauntalltirol & Galtirit & Griesskogel $19 x$ & GAUSS-KRŪGER M28 see belov"!!! & $E$ & \\
\hline & Innere Biefenbach & Austria & Ischgl & Paznauntalltirol & |lschgl & Innere_Riefenbach_쪼 & GAUSS-KRŪGER M28 see belov!!!! & $\mathrm{E}$ & \\
\hline & Lochmahd & Austria & Ischgl & Paznauntallt Tirol & |sohgl & Loch & GAUSS-KRŪGER M28 see belov!!!! & $\mathrm{E}$ & \\
\hline & Platteimähder & Austria & |schg| & PaznauntalfTirol & Ischgl & Platt, & GAUSS-KRÜGERR M28 see belov!!!! & $E$ & \\
\hline & metlen 741229 & $\mathrm{CH}$ & Engi & Glarus & Mettlenruns & 1174 (Elm) & WGS84:9. $7^{\prime} 51.7^{\prime \prime}+46^{\prime} 58^{\prime} 19.9^{\prime \prime}$ & multiple avalanche event (medium) & natural deflected in the \\
\hline & mettlen $741230 \mathrm{a}$ & $\mathrm{CH}$ & Engi & Glarus & Mettlenruns & $1174(E \mid m)$ & WGS84: $9^{\prime} 7^{\prime} 51.7^{\prime \prime}+46^{\prime} 58^{\prime} 19.9^{\prime \prime}$ & multiple avalanche event(mediuml) & natural deflected in the \\
\hline & metlen $741230 \mathrm{~b}$ & $\mathrm{CH}$ & Engi & Glarus & Mettlenruns & $1174(\mathrm{Elm})$ & WGS84: $9^{\prime} 7^{\prime} 51.7^{\prime \prime}+46^{\circ} 58^{\prime} 19.9^{\prime \prime}$ & multiple avalanche event(mediumi) & natural deflected in the \\
\hline & mettlen 77 & $\mathrm{CH}$ & Engi & Glarus & Metclenruns & $1174($ Elm) & WGS84: $97^{\prime} 51.7^{\prime \prime}+46^{\circ} 58^{\prime} 19.9^{\prime \prime}$ & multiple avalanche event (medium) & natural deflected in the \\
\hline & mettlenruns 78 & $\mathrm{CH}$ & Engi & Glarus & Mettlenruns & $1174($ Elm) & WGS84: $9^{\prime} 7^{\prime} 51.7^{\prime \prime}+46^{\circ} 58^{\prime} 19.9^{\prime \prime}$ & multiple avalanche event(medium)] & natural deflected in the \\
\hline & mettlen 810104 & $\mathrm{CH}$ & Engi & Glarus & Mettlenruns & 1174 (Elm) & WGS84: $97^{\prime} \cdot 51.7^{\prime \prime} / 46.58^{\prime} 19.9^{\prime \prime}$ & multiple avalanche event(small) & natural deflected in the \\
\hline & mettlen 810105 & $\mathrm{CH}$ & Engi & Gilarus & Mettlenruns & $1174[$ Elm] & WGS84:9.7 $51.7^{\prime \prime}+46^{\circ} 58^{\prime} 19.9^{\prime \prime}$ & multiple avalanche event (small]) & natural deflected in the \\
\hline & mettlen $810310 \mathrm{a}$ & $\mathrm{CH}$ & Engi & Glarus & Mettlenruns & 1174 [Elm] & WGS84: $9^{\prime} 7^{\prime} 51.7^{\prime \prime}+46^{\circ} 58^{\prime} 19.9^{\prime \prime}$ & multiple avalanche event (small) & natural deflected in the \\
\hline & mettlen_810311 b & $\mathrm{CH}$ & Engi & Glarus & Mettlenruns & 1174 (Elm) & WGS84: $9^{\prime} 7^{\prime} 51.7^{\prime \prime}+46^{\circ} 58^{\prime} 19.9^{\prime \prime}$ & multiple avalanche event (small) & natural deflected in the \\
\hline & metclen_820130 & $\mathrm{CH}$ & Engi & Glarus & Mettlenruns & 1174 (Elm) & WGS84: 9. $7^{\circ} 51.7^{\prime \prime}+46^{\circ} 58^{\prime} 19.9^{\prime \prime}$ & multiple avalanohe event (medium) & natural deflected in the \\
\hline & mettlen_820704 & $\mathrm{CH}$ & Engi & Glarus & Mettlenruns & 1174 [Elm) & WGS84: $9^{\prime} 7^{\prime} 51.7^{\prime \prime}+46^{\circ} 58^{\prime} 19.9^{\prime \prime}$ & multiple avalanche event (me dium) & natural deflected in the \\
\hline & mettlen 880313 & $\mathrm{CH}$ & Engi & Glarus & \begin{tabular}{|l} 
Mettlenruns \\
Ments
\end{tabular} & 1174 [Elm) & WGS84: $9^{\prime} 7^{\prime} 51.7^{\prime \prime}+46^{\circ} 58^{\prime} 19.9^{\prime \prime}$ & multiple avalanche event (small) & natural deflected in the \\
\hline & mettlen 880321 & $\mathrm{CH}$ & Engi & Glarus & Mettlenruns & 1174 (Elm) & WGS84: $9^{\prime} 7^{\prime} 51.7^{\prime \prime}+46^{\prime} 58^{\prime} 19.9^{\prime \prime}$ & multiple avalanche event (small) & natural deflected in the \\
\hline 22 & mettlen 84 & $\mathrm{CH}$ & Engi & Glarus & Mettlenruns & 1174 (Elm) & WGS84:9.7 $71.7^{\prime \prime}+46^{\prime} 58^{\prime} 19.9^{\prime \prime}$ & multiple avalanche event (small) & natural deflected in the \\
\hline 23 & mettlen_86 & $\mathrm{CH}$ & Engi & Glarus & Mettlenruns & 1174 (Elm) & WGS84: $9^{\prime} 7^{\prime} 51.7^{\prime \prime}+46^{\prime} 58^{\prime} 19.9^{\prime \prime}$ & multiple avalanche event (medium) & natural deflected in the \\
\hline & mettlen 870228 & $\mathrm{CH}$ & Engi & Gilarus & Mettlenruns & 1174 [Elm) & WGS84: $9^{\prime} 7^{\prime} 51.7^{\prime \prime}+46^{\circ} 58^{\prime} 19.9^{\prime \prime}$ & multiple avalanche event (small), & natural deflected in the \\
\hline & mettlen 870302 & $\mathrm{CH}$ & Engi & Gilarus & Mettlenruns & 1174 [Elm] & WGS84: $9^{\prime} 7^{\prime} 51.7^{\prime \prime}+46^{\circ} 58^{\prime} 19.9^{\prime \prime}$ & multiple avalanche event (medium) & natural deflected in the \\
\hline & mettlen_89 & $\mathrm{CH}$ & Engi & \begin{tabular}{|l} 
Gilarus \\
\end{tabular} & \begin{tabular}{|l|} 
Metlenruns \\
\end{tabular} & 1174 (Elm) & WGS84: $9^{\prime} 7^{\prime} 51.7^{\prime \prime}+46^{\prime} 58^{\prime} 19.9^{\prime \prime}$ & multiple avalanche event (small) & natural deflected in: \\
\hline & mettlen_91 & $\mathrm{CH}$ & Engi & Glarus & Metclenruns & 1174 (Elm) & WGS84:9.7. $51.7^{\prime \prime}+46^{\circ} 58^{\prime} 19.9^{\prime \prime}$ & multiple avalanche event (mediuml) & natural deflected in the \\
\hline 28 & mettlen 92 & $\mathrm{CH}$ & Glarus & \begin{tabular}{|l} 
Engi \\
\end{tabular} & Metclenruns & $1174(\mathrm{Elm})$ & WGS84: $9^{\prime} 7^{\prime} 51.7^{\prime \prime}+46^{\prime} 58^{\prime} 19.9^{\prime \prime}$ & multiple avalanche event (large) & natural deflected in the \\
\hline & 14 Dryadbreen & Norway & Sualbard & Fardalen & Dryadbreen & Polarinstituttet & WGS84:33, 867200, 508000 & Deflected & natural deflected in the \\
\hline 30 & 3 Bilise & Norway & Mere og Riomsdaler & Rise & Korsafonna & 1293 III(Hiarundffiord) & WGS584:32Y LP 685003 & Enstreme & \\
\hline 31 & 13Yassdalen & Norway & Troms & Vassdalen & Storebalak & $1432 \mathrm{ll|}$ (Gratangen]) & WGS84:XS 150090 & Exstreme & \\
\hline 32 & 4Eleis & Norway & Hordaland & Ullenswang & Bleie & 1315 Iㅣ (Odda) & WGS84:32VLM 630812 & Enstreme & \\
\hline & Jamtefonna & Norway & More og Riomsdalen & Yalldalen & Jamtefonna & $1319 \mathrm{VV}$ & WGS84: 32V MQ110103 & Exstreme & $10 \mathrm{~m}$ river embankmer \\
\hline & Hattavarre 01 & Norway & Troms & Balsfiord & Bjerklund & 15331(Tamokdalen) & WGS84: 34W DB 403624 & Esstreme & \\
\hline & Elsk95 & leeland & Vestfirsioi & Flateyri & Skollahvilft & flat & & Exstreme & \\
\hline 1 & $\backslash$ ark1 & Ark2 $/$ Ark & & & & & 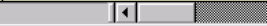 & & 11 \\
\hline Kla & & & & & & & $\mid \Gamma$ & & \\
\hline
\end{tabular}

Fig. 1. EU CADZIE database internet page and MS Excel database overview. 

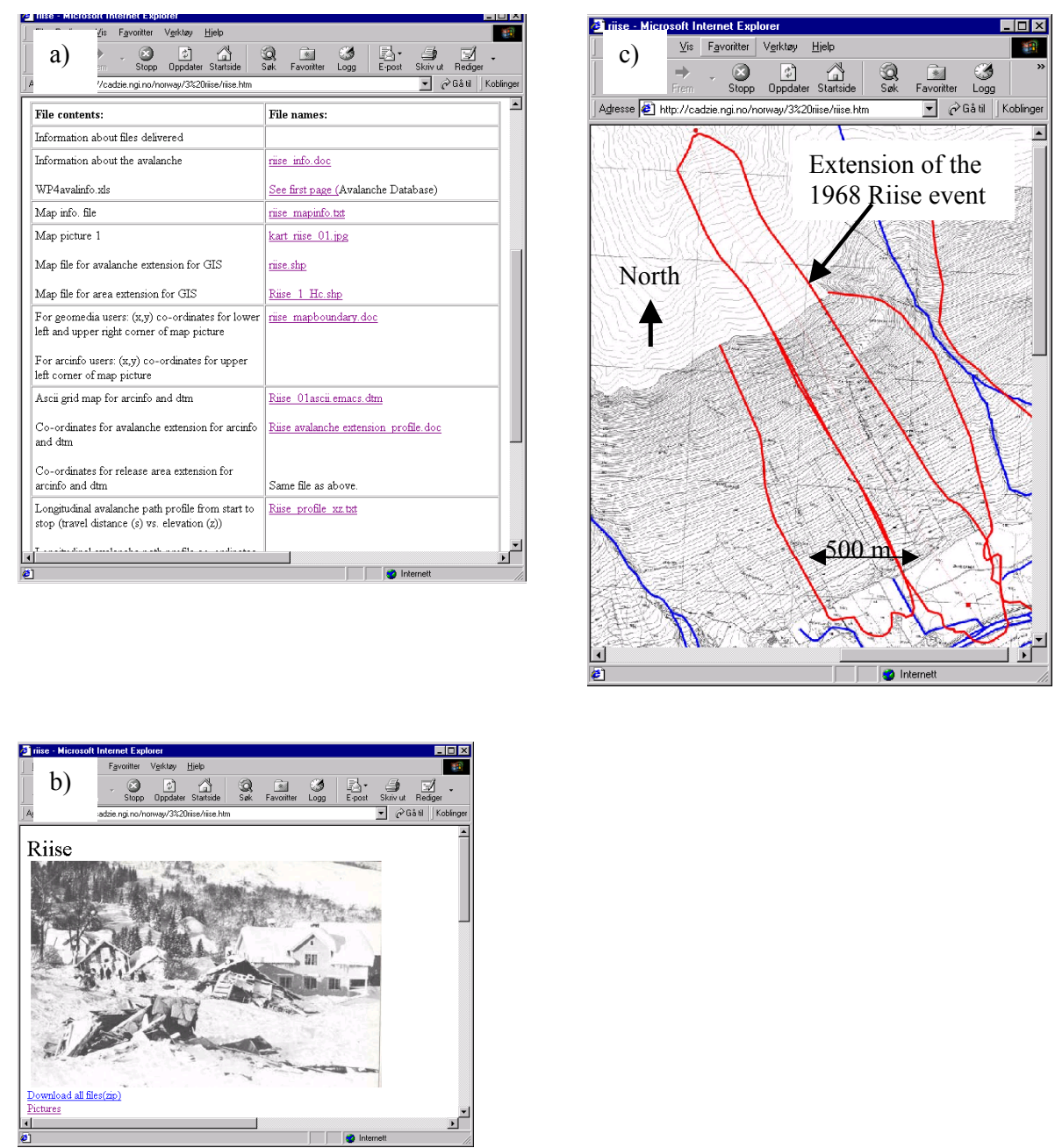

Fig. 2. Example of avalanche event sub-page list (a) with links to pictures (b), maps with observed avalanche extension (c), and other relevant information. The selected example is for the 1968 Riise avalanche event. The contour line interval is $20 \mathrm{~m}$ above $600 \mathrm{~m}$ a.s. 1 . and $5 \mathrm{~m}$ below $600 \mathrm{~m}$ a.s.1.

format), and digital terrain as rectangular grids in ASCII format, also structured for ArcView/Info. Complementary files to present the extension of the release area and the observed avalanche are also included. A surfer has proved to be convenient for production of rectangular grids and vectorised maps from raw terrain data. The Surfer grid files (.grd ) can easily be restructured (mirrored) to ArcView/Info.

\subsection{Contents}

The goal during the period of CADZIE is to have all relevant information on at least five extreme and five deflected avalanche events in each of the participating countries, i.e. altogether data on sixty events collected in the database.

Each avalanche is identified by a specific name and its location (country, region and nearest village), as well as time of occurrence. Map name, general map information, and UTM coordinates follow. The database separates extreme avalanches from deflected avalanches. For deflected avalanches, it is further indicated whether the deflection is caused by a natural or a manmade deflecting dam.

The events are classified as powder snow avalanches, dry dense snow avalanches, and wet dense snow avalanches. Relevant information on release area and aspect, avalanche volume, runout (vertical height and horizontal length, runout angle), and entrainment are presented, followed by a brief description of the termination in the valley and the resulting damages. Separate files with digital maps and terrain, also showing the extension of the release area and the observed avalanche, are included as described above. Also, the longitudinal terrain profile is included for computational use, to enable a quick impression of the characteristics of the path.

Additional information, such as photos, historical descriptions and reports, are included as separate files, Figs. 2a and b. Special focus is given to detailed photos that show, for example, traces on trees and houses from which the height of the avalanche cloud can be deduced, or thickness of snow from the cloud on house walls, etc. Standard meteorological data are included to study the release conditions (direc- 


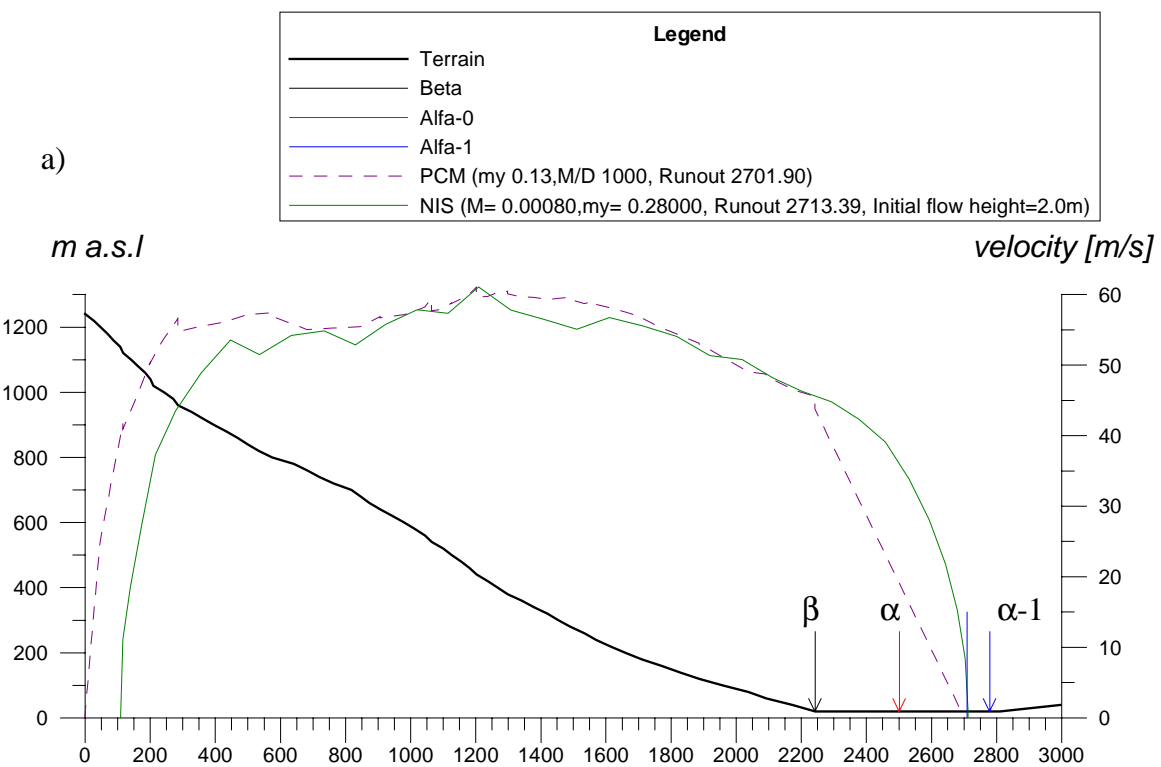

Horizontal distance $[\mathrm{m}]$ (scale 1:15000)

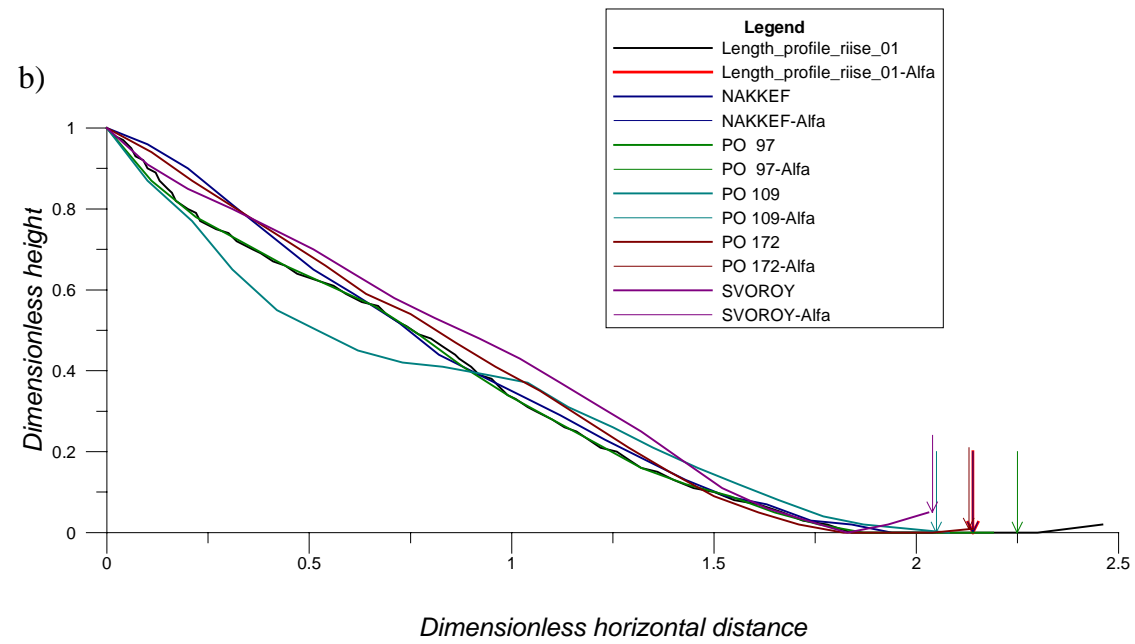

Fig. 3. Computational results for the 1968 Riise avalanche with statistical/topographical and dynamical models (a), and comparative model (b).

tion, speed and duration of wind; precipitation over the last 1,3 and 5 days; temperature, air humidity, and clouds prior to release). Possible snow profiles (snow height, stratification, grain type and size, temperature, density, hardness, water content, etc.) are attached in separate files. Finally, future analyses, example calculations and simulations related to events in the database will be attached in separate files.

The reliability or uncertainty is quantified for all the relevant parameters in the database. Moreover, for each event the providers of maps, (to be contacted for further use) is given, together with correct citation and a contact person for all the data.

\section{Applications of the database}

4.1 Intention and information on the applied database events

Most of the possible applications of the database listed in the previous section are meant for later and more thorough analyses that can be performed when the EU CADZIE database is more complete. Hence, this section is limited to providing an idea of how the database can be applied to gain empirical knowledge on the dynamics of extreme avalanche runout and deflection. 

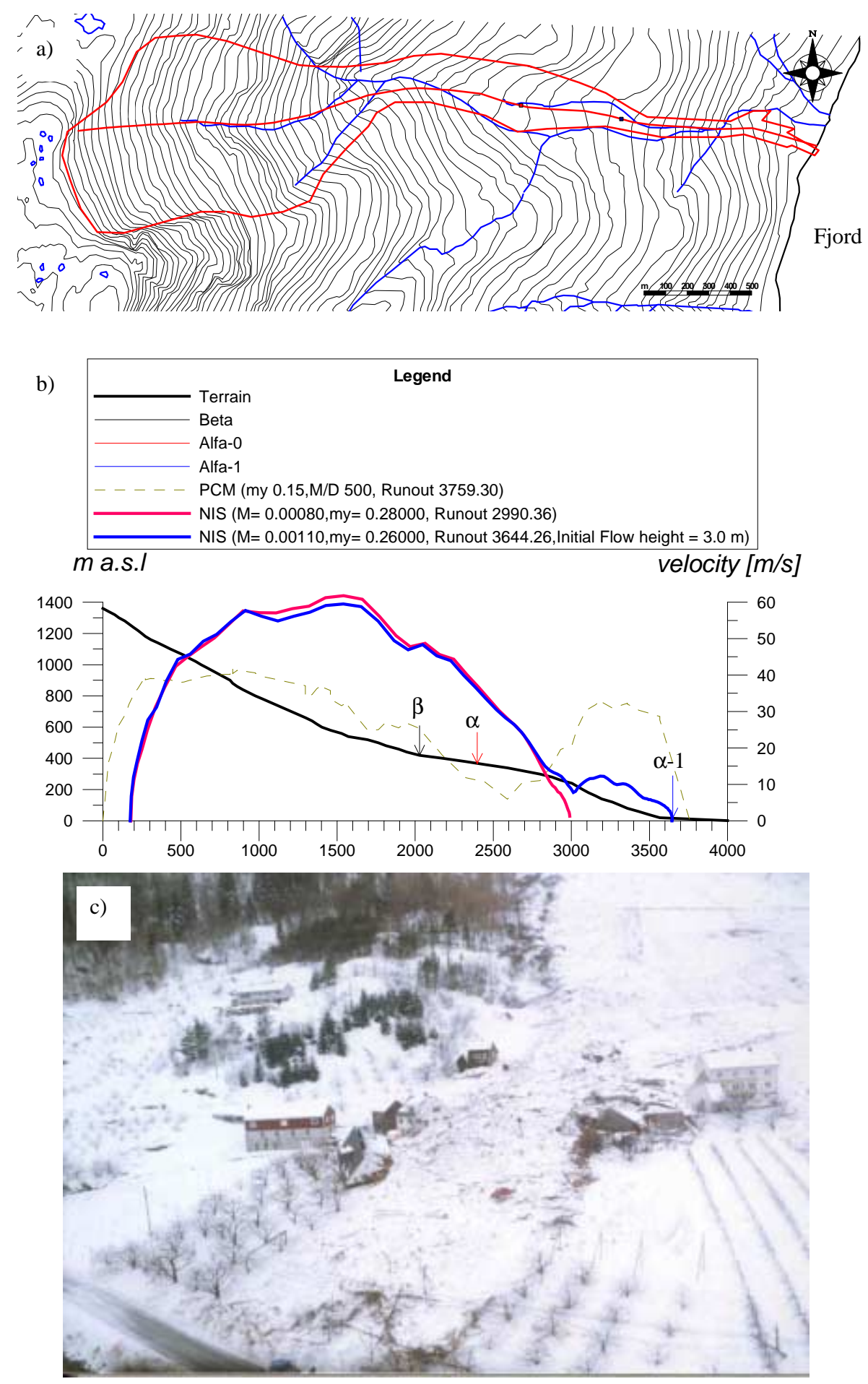

Fig. 4. Topographic map for the 1994 Bleie avalanche with contour line interval $20 \mathrm{~m}$ (a), computational results with statistical/topographical and dynamical models (b), and picture of damages (c).

All the events discussed below are included in the EU CADZIE database. However, for statistical/topographical and comparative models a more comprehensive database on extreme events is needed. Hence, the Norwegian database with path profiles and runout distances for more than 200 events is applied in addition to the EU CADZIE database.
This illustrates the need to include links to other existing databases in the EU CADZIE database.

Statistical/topographical models assume that there are small variations in the physical snow parameters giving the longest runout distance. This assumption is valid only within one climatic region (McClung et al., 1989). Hence, such 
links and/or a more comprehensive EU CADZIE database would also help to develop statistical/topographical and comparative models for other regions. Statistical/topographical models have previously been applied also in Austria (Lied et al., 1995), Iceland (Jóhannesson, 1998) and in the Spanish Pyrenees (Furdada and Vilaplana, 1998). The significance of historical records for hazard zoning in terms of conditions influencing the avalanche occurrences is discussed by Kristensen et al. (in press), while probability analysis and uncertainty in hazard zoning are discussed by Barbolini and Savi (2001) and Harbitz et al. (2001).

As examples of extreme avalanches, the following Norwegian events are selected:

- The 1968 Riise avalanche, Ørsta, western Norway, started at $1250 \mathrm{~m}$ a.s.1. and finally travelled $470 \mathrm{~m}$ across the horizontal valley bottom at $15 \mathrm{~m}$ a.s.1., Fig. 2c. The travel distance was $3000 \mathrm{~m}$ (horizontal projection $2710 \mathrm{~m}$ ). The inclination of the release area was $45^{\circ}$. The avalanche destroyed the forest in the path down the mountainside and 17 houses around the farm at Riise, Fig. 2b. Three people died and eight survived in the houses. It was snowing the whole week before the accident, causing great avalanche danger in the whole area. Snow observations in the valley indicated a snow depth of approximately $2 \mathrm{~m}$, with a lot of loose snow in the upper parts of the snow cover.

- The 1994 Bleie avalanche, western Norway, has an estimated return period of 1000 years, based on weather statistics and confirmed by the records of the harvest of the farms (Lied et al., 1998). The horizontal runout distance was about $3600 \mathrm{~m}$, corresponding to a runout angle of $20^{\circ}$, Fig. 4a. The avalanche crossed a gentle field of about $800 \mathrm{~m}$ before it passed a "shoulder" along the path profile at $300 \mathrm{~m}$ a.s.1. and continued to the fjord. Three farms were partly destroyed, Fig. 4c. The measured precipitation during the week prior to the avalanche indicates a snow height in the release area of $3 \mathrm{~m}$. In 1721, an avalanche stopped at Reiseter, located at the "shoulder".

- The 1995 Drevja avalanche, northern Norway, started $600 \mathrm{~m}$ a.s.1. and passed a $15-20 \mathrm{~m}$ high natural catching dam at $300 \mathrm{~m}$ a.s.1., Fig. 5a. The width of the avalanche in the track was about $200-400 \mathrm{~m}$. Between $150 \mathrm{~m}$ a.sl. and the valley bottom at $20 \mathrm{~m}$ a.sl., the avalanche destroyed a dense mixed forest (spruce, pine, and birch). The avalanche crossed the road, and stopped at the other side of the river. The 1995 event was released after heavy snowfall the week before. A similar avalanche occurred in 1921. The story relates further that the local people gathered to collect the broken trees for firewood.

As an example of a deflected avalanche, the following is used:

- The 2001 Dryadbreen avalanche, $10 \mathrm{~km}$ SW of Spitsbergen, Svalbard. The release area under the mountain Håbergnuten, south of the glacier Dryadbreen in
Fardalen, was about $300 \mathrm{~m}$ long with an inclination of $35^{\circ}-45^{\circ}$, Fig. 6a. Beneath the release area there is first a ridge splitting the avalanche, before the main part of the avalanche is deflected on a secondary moraine ridge with a vertical height of 9-12 $\mathrm{m}$ measured in a vertical plane perpendicular to the centre-line of the ridge. Two persons on snow-scooters were killed in the avalanche. However, other avalanches in the same area indicate a natural release after strong winds (wind gusts of $30 \mathrm{~m} / \mathrm{s}$ ). The snow profile shows a layer of coarse depth hoar close to the ground, covered by wind transported snow. Measurements, however uncertain due to wind exposure, revealed $5 \mathrm{~mm}$ of precipitation the last two days before the avalanche.

\subsection{Computational methods}

The computations are made by use of the graphical user interface "SKRED". This interface has been recently developed at the Norwegian Geotechnical Institute (NGI). Basically, the interface is an assembly of avalanche computational models for practical use based on more than twenty years of research. The interface is programmed in Visual Basic and covers:

1. Statistical models: topographical $\alpha / \beta$-model and comparative model;

2. ACCESS database on Norwegian extreme avalanches;

3. Dynamical models: PCM-, PLK-, NIS1- and NIS2models;

4. Dynamical/empirical deflecting dam model;

5. Use of terrain profiles from digital maps (GIS);

6. Model descriptions for report appendices, etc.;

7. Link to the Norwegian Building Act Legislation Internet pages.

The models embraced in "SKRED" and applied in this study are briefly described in Appendix A. Harbitz (1998) presents a more extended description of the various models.

\subsection{Use of databases to study extreme avalanche runout}

The 1968 Riise avalanche was considered an "extreme event". However, the first experience to be gained from the databases is that the observed horizontal travel distance of $2710 \mathrm{~m}$ (corresponding to a runout angle $\alpha_{\text {measured }}=24.6^{\circ}$ ), is less than one standard deviation beyond the mean runout angle calculated by the $\alpha / \beta$-model, Fig. 3a. Likewise, results from the dynamical PCM block model are in good agreement with the observations for normal input values $\mu=0.13$ and $M / D=1000 \mathrm{~m}$. For the dynamical NIS1 deformable body model, good agreement with the runout distance is achieved with normal shear viscosity and friction values $\left(M=0.00080 \mathrm{~m}^{2}, \mu=0.28\right)$, and initial flow height 
a)

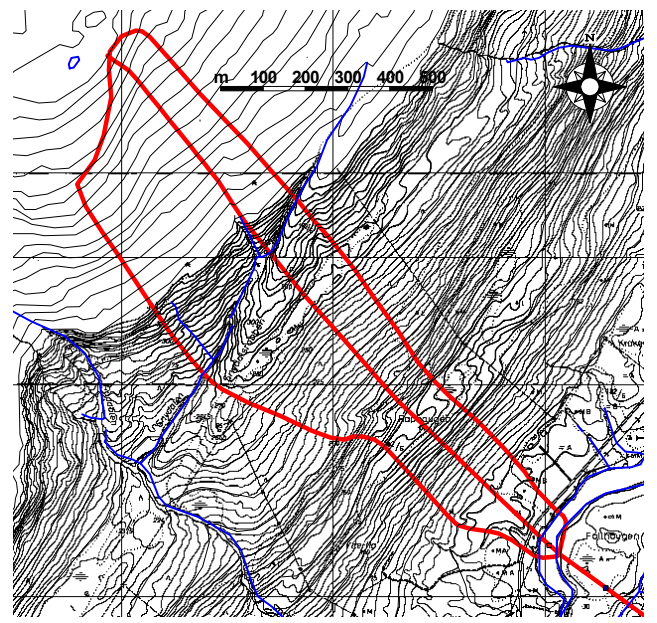

b) Drevja_length_profile $15 \mathrm{~m}$ catching dam

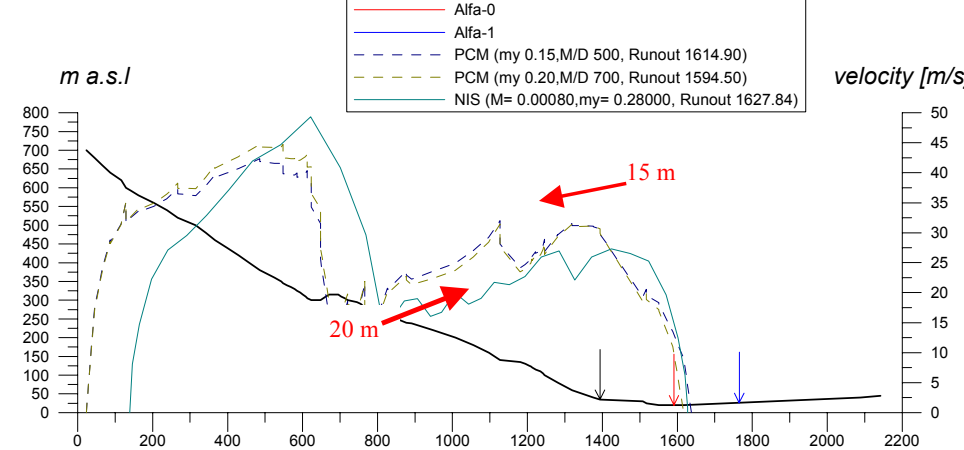

c)

Drevja_20m_dam

$m$ a.s.I
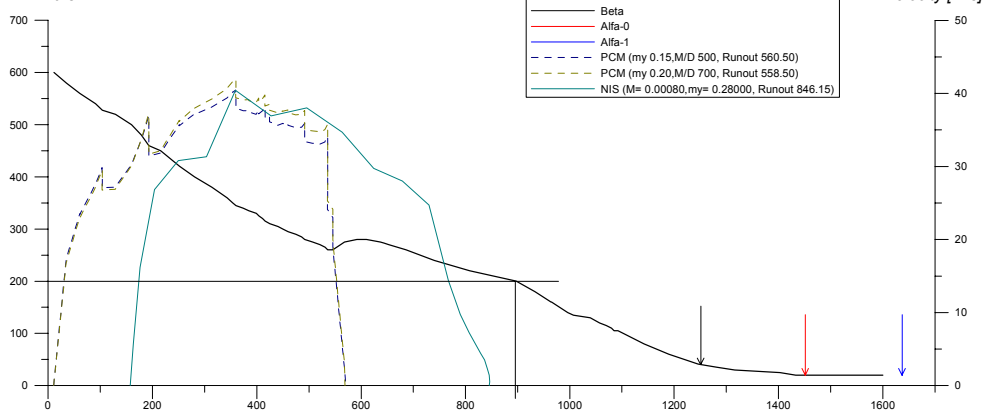

Horizontal distance [m] (scale 1:5000)

d) Drevja_length_profile

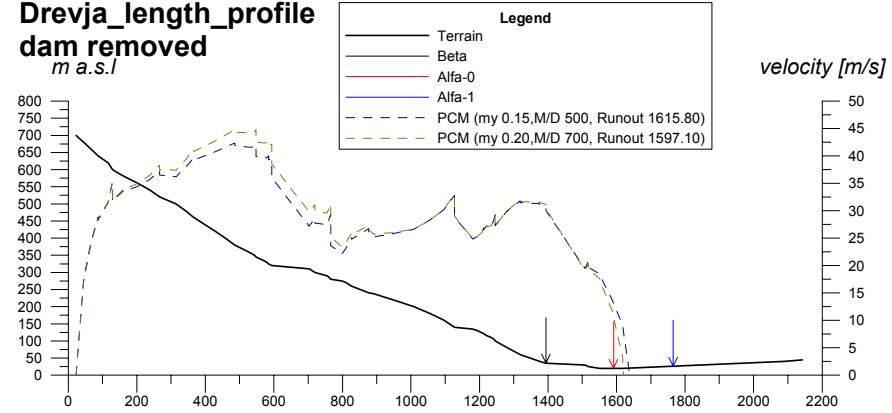

Horizontal distance [m] (scale 1:10000)
U. Domaas et al.: The EU CADZIE database 
$2.0 \mathrm{~m}$. Both the dynamical models give maximum frontal velocity of more than $60 \mathrm{~m} / \mathrm{s}$, in agreement with velocities measured for other large avalanches (e.g. Aulta in Switzerland and Ryggfonn in Norway). Hence, the considerable runout distance in flat terrain is easily obtained with normal parameter values, indicating that such an event is highly relevant for hazard zoning.

For the 1968 Riise avalanche, which had a relatively parabolic path profile, the comparative model has also been used, Fig. 3b. This model calculates an actual runout angle of $25^{\circ}$ based on observed runout angles in the most similar paths in the Norwegian database. This is only $50 \mathrm{~m}$ shorter than the observed distance, or less than $2 \%$ of the horizontal runout distance. The Riise path has a vertical height of $1235 \mathrm{~m}$, while the five most similar avalanche paths have a vertical path height of $950-1150 \mathrm{~m}$, and a runout angle $\alpha_{\text {measured }}$ of $25.0-26.0^{\circ}$. This illustrates the value of the comparative model and confirms the relevance of such an event for hazard zoning based on "extreme" avalanches.

For the 1994 Bleie avalanche, the observations correspond to one standard deviation beyond the mean runout angle calculated by the $\alpha / \beta$-model, Fig. 4b. In other words, the statistical/topographical model again indicates that such an "extreme" runout distance should be considered for hazard zoning, even though the "path shoulder" is located $400 \mathrm{~m}$ beyond the mean runout angle $\alpha$. The dynamical NIS1 model is sensitive to the input parameter values and can easily be tuned to agree with the observations. However, reducing the dry friction slightly from $\mu=0.28$ to $\mu=0.26$ is enough to reproduce the observations. Again, the statistics based on the databases combined with the simulations reveal that such a runout distance should clearly be considered for hazard zoning. This is confirmed by the fact that another avalanche in 1750 continued all the way to the farm, Reiseter, located at the "path shoulder". This runout distance is reproduced with the normal default values for the NIS1 model, Fig. 4b. Another experience to be gained by back-calculations of the Bleie event is that the PCM block model most probably accelerates too quickly over the shoulder, producing an unrealistic velocity profile in such terrain.

For the 1995 Drevja avalanche, the observations correspond to the mean runout angle calculated by the $\alpha / \beta$-model, Fig. 5b. In the SW part of the track, where the natural dam is $20 \mathrm{~m}$ high, the avalanche is clearly affected, Figs. 5a and c, as opposed to the NE part, where the dam is only $15 \mathrm{~m}$ high, Figs. 5a and $b$. The PCM and NIS1 dynamical models show that the avalanche first reaches a maximum velocity of about $45 \mathrm{~m} / \mathrm{s}$ above the natural catching dam, at which the velocity is reduced to about $20 \mathrm{~m} / \mathrm{s}$, Fig. $5 \mathrm{~b}$. Note that the avalanche again reaches a velocity of about $30 \mathrm{~m} / \mathrm{s}$ further down, before it comes to stop across the river, in agreement with the observations. Recalculations by the PCM model, with the dam artificially removed, reveal the same stopping position, Fig. 5d. The important experience to be gained is that if a dam in the upper track is too low to stop the avalanche, the dam does not affect the runout distance. The avalanche seems to obtain the same maximum velocity below the dam with or without the catching dam. Another observation is that in the SW part, where the catching dam is $20 \mathrm{~m}$ high, the PCM model stops the avalanche at the dam, while the NIS1 model seems to handle the passing of the dam fairly well and returns a stopping position $250 \mathrm{~m}$ further down the slope (50 $\mathrm{m}$ too short compared to the observations), Fig. $5 \mathrm{c}$. The back-calculations also demonstrate the importance of using several dynamic models in hazard zoning.

\subsection{Use of databases to study avalanche deflection}

For the 2001 Dryadbreen avalanche, Figs. 6a and c, backcalculations are made by the deflection dam model. The calculated centre-of-mass run-up height is $8.0 \mathrm{~m}$, Fig. $6 \mathrm{~d}$. To compensate for the limitations of a centre-of-mass consideration, the run-up height is subsequently calibrated utilising observations of nine full-scale avalanches influenced by natural or manmade deflecting dams. The calibrated run-up height is about $10.5 \mathrm{~m}$, Fig. 6b, in close agreement with the field observations described above. In spite of the subjective evaluation needed for the energy dissipation at impact, the centre-ofmass model in combination with the calibration procedure seems to reduce the uncertainties in the calculations of runup heights on deflecting dams. The calibration procedure is a typical example of the benefit of such a database. Impact, energy dissipation and shocks are discussed further by Harbitz et al. (2000), Jóhannesson (2001), and Tai et al. (2001).

\section{Concluding remarks}

The EU CADZIE database is a contribution to meet the needs for improved avalanche hazard zoning by computational models and improved understanding of the interaction between defence structures and avalanches. The database contains information on well-documented, extreme or deflected avalanche events in the six countries of the partners of the EU programme CADZIE.

Example calculations of extreme and deflected events made by the NGI user interface "SKRED", for practical use of avalanche computational models, present applications of the database. The results reveal that dramatic events in large avalanche tracks are not so extreme when analysed by statistical/topographical or dynamical models. All runout lengths are within one standard deviation beyond the mean runout angle of the statistical/topographical model or easily obtained with normal parameter values for the dynamical models. Hence, all these dramatic events are highly relevant for hazard zoning.

The examples also demonstrate the need for more welldocumented events to be included in the database for improved statistical analyses, as well as validation and calibration of the dynamical models. It is hoped that the database can be open to the public, at least for research use, with links to the other databases in each country. This may be achieved by governmental funding of database development and maintenance. 

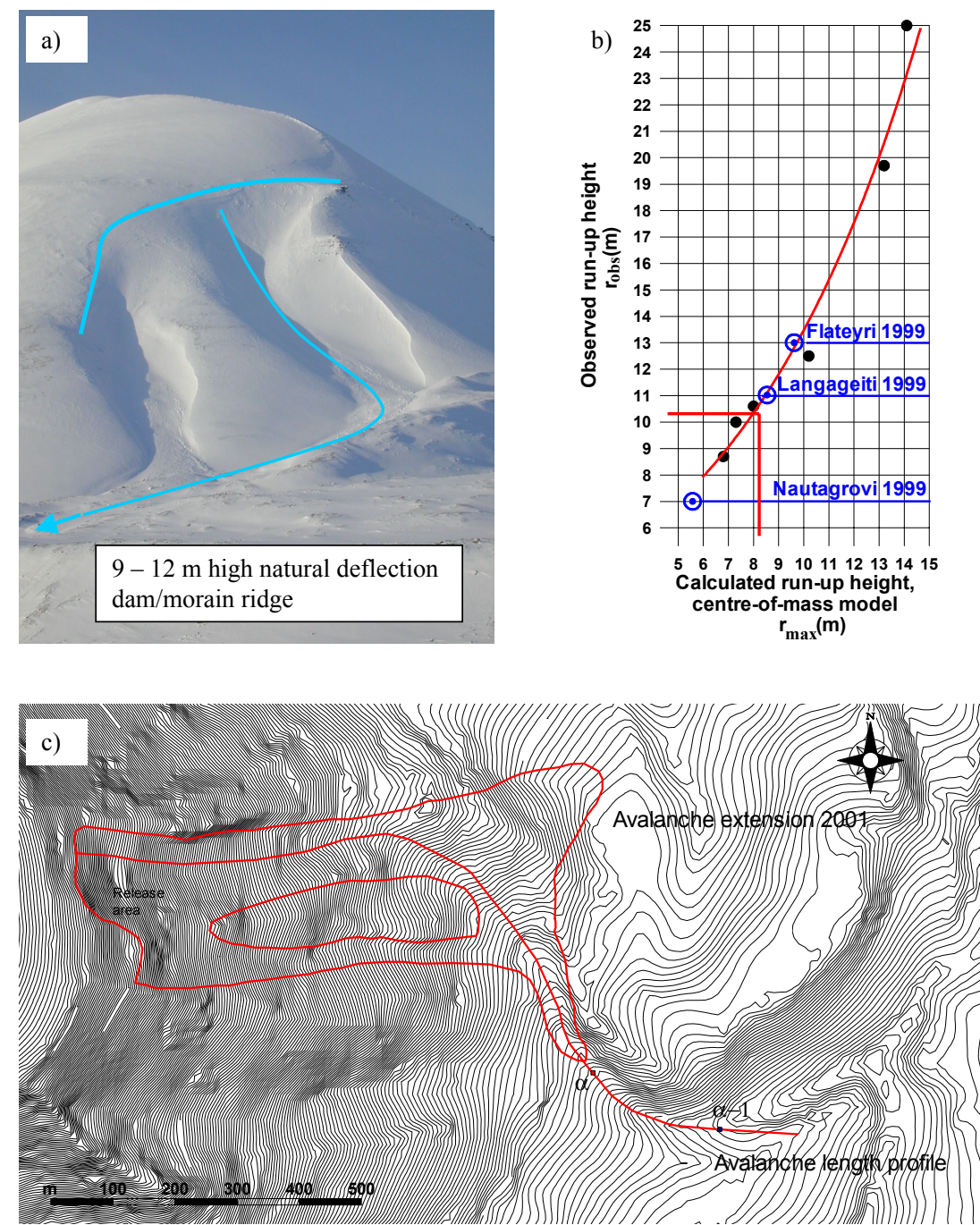

d)

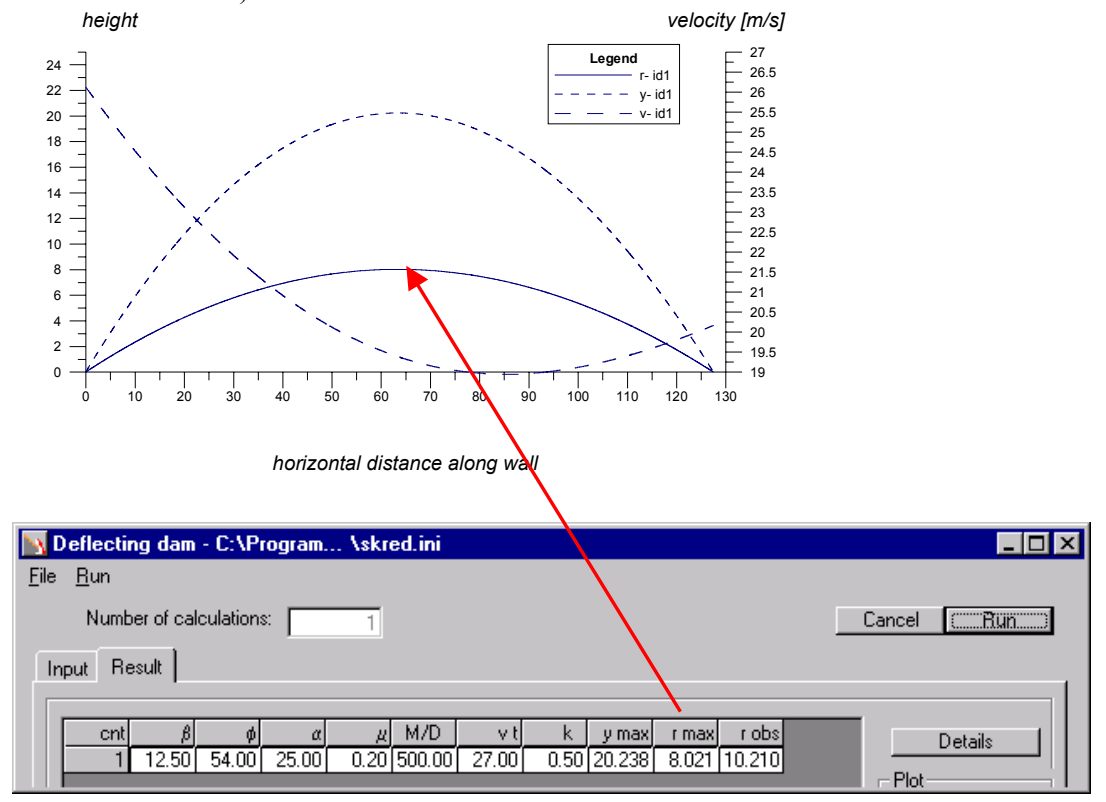

Fig. 6. Picture of the 2001 Dryadbreen avalanche track (a), best-fit line for observed vs. calculated run-up heights (b), topographic map with contour line interval $2 \mathrm{~m}$ (c), and computational results with deflection dam model (d). 
The examples further reveal the importance of focusing on the probability and uncertainty in hazard zoning, as well as improved models for design and location of deflection dams. In general, the shortcomings of today's dynamical models are the limited insight into initial conditions and rheological laws, as well as the neglect of snow entrainment and flow regime transitions, including the formation of a suspension layer ("snow cloud").

The ongoing work on avalanche deflection has shown that energy dissipation during avalanche/dam interaction is not well understood. Important factors determining the deflection rate are snow properties and avalanche speed that influences compression and energy dissipation at impact, as well as the dam geometry. The deflected avalanches in the database will hopefully contribute to an increased understanding of these processes.

\section{Appendix A Brief description of the models embraced in "SKRED" and applied in this study}

The statistical/topographical $\alpha / \beta$-model (e.g. Bakkehøi et al., 1983) governs maximum runout distance solely as a function of topography. The runout distance equations are found by regression analysis, correlating the longest registered runout distance from more than 200 Norwegian avalanche paths to a selection of topographic parameters. The most usual form of the $\alpha / \beta$-model based on the Norwegian database is that of a simple linear regression relation: $\alpha=0.96 \beta-1.4^{\circ}$, where the runout angle $\alpha$ is the average gradient of the avalanche path, and $\beta$ is the average inclination of the avalanche path between the starting point and the point of $10^{\circ}$ inclination along the path profile. The standard deviation is $2.3^{\circ}$ and the correlation coefficient is 0.92 .

The comparative model (Bakkehøi and Norem, 1993; 1994) computes the runout angle by comparing the actual path profile with more than 200 Norwegian paths with registered avalanche runout. Each avalanche path is described by $n$ characteristic parameters weighted by suitable coefficients. An $n$-dimensional weighted distance expresses the similarity between the two paths. A small weighted distance indicates a high degree of similarity. The actual runout angle is finally calculated as the average of the runout angles of a specified number of the most similar registered avalanche path profiles. The standard deviation of the calculated runout angle from the observed runout angle for all the registered avalanches is $1.86^{\circ}$, which is better than the standard deviation of the statistical/topographical $\alpha / \beta$-model and the dynamical NIS1 model. The comparative model also affords the opportunity to study the background material of the most similar registered avalanche events with regard to topographical conditions, region, climate, return period, etc. Hence, it is possible to attach greater importance to selected registered events.

The PCM model (Perla et al., 1980) describes the avalanche as a block moving on a path of varying inclination. The reference point is the initial rest position of the block's centre-of-mass. The equation of momentum includes gravity, velocity-independent dry (Coulomb) friction $\mu$, as well as the centrifugal force due to curvature of the path, dynamic drag and inertia-resistive ploughing of snow masses in the front. The three latter contributions are implemented together as the velocity squared, divided by the $M / D$ "mass-to-drag" ratio. The momentum equation is solved by an iterative solution procedure, dividing the slope into small linear segments of different inclination. The usefulness of the model depends on knowledge of the two adjustable parameters (dry friction coefficient and mass-to-drag ratio) that can vary considerably. These values have been limited to some extent by testing the model statistically.

The NIS1 model (Irgens, in review) describes the avalanche as a deformable body model of which velocity and flow height are a function of both space and time. The snow is described as a visco-plastic material with dispersive pressure, (i.e. the normal stresses depend on the shear rate), forming a shear flow with or without a basal slip velocity. Varying inclination produces centrifugal forces. The model is onedimensional, as the equations are depth-averaged for a velocity profile assumed to be identical in form to the steady shear flow profile. The resulting equations for balance of mass and linear momentum are solved by a Eulerian finite difference mid-point scheme in space and a fourth-order Runge-Kutta procedure in time.

The deflecting dam model (Harbitz et al., 2000) describes the motion of the avalanche centre-of-mass along the side of a retaining dam. Strictly speaking, the centre-of-mass is that of a representative frontal part of the slide projected onto the terrain (the total avalanche centre-of-mass may not even reach the dam). The equations are derived from classical mechanics, including a resistance force represented by a dynamic drag and a dry (Coulomb) friction, and are solved numerically by a fourth order Runge-Kutta procedure. However, a lumped mass consideration does not include any effects of the avalanche extension on the dynamics. Hence, the model results will in any case be encumbered with obvious restrictions. Instead of a sophisticated digital terrain model, the model, therefore, applies a simplified geometry to study the influence of avalanche impact velocity, terrain inclination, dam configuration, and dam orientation on avalanche course deflection and run-up height along a deflection dam. An additional advantage of a simplified geometry study is that the deflecting dam does not have to be superimposed on a complex digital terrain. The avalanche impact velocity on the dam is normally found by running the PCM model. The effects of energy loss due to impact may also be investigated by the deflecting dam model. To overcome the model deficiencies introduced by a lumped mass consideration, a best-fit line between the observed and the calculated run-up heights is applied in practical dam design. At present, the calibrated model is based on nine deflected dense snow avalanches and three powder avalanches.

Acknowledgements. This paper is a contribution to the NGI Strategic Institute Programme "200011001-SIP6 snow avalanches", 
funded by the Research Council of Norway, and the EU programme "Catastrophic Avalanches: Defence Structures and Zoning in Europe", partly funded by the European Union under the contract no. EVG1-CT-1999-0009. The authors are indebted to Steinar Bakkehøi (NGI) for GIS and WEB design, to R. Opsahl (Telesafe Consulting AS, previously NGI) for his programming of the graphical user interface "SKRED", to T. Gregory (NGI) for revising the manuscript, and to T. Jóhannesson and K. M. Hákonardóttir (Icelandic Meteorological Office), M. Maggioni, F. Tiefenbacher and U. Gruber (Swiss Federal Institute for Snow and Avalanche Research), T. Tartarotti, K. Kleemayr and S. Wieshofer (IWL-BOKU), N. Mohamed (CEMAGREF), P. Sampl (AVL GmbH), and R. Sailer (Austrian Institute for Torrent and Avalanche Research) for their contributions to the EU CADZIE database.

\section{References}

Bakkehøi, S., Domaas, U., and Lied, K.: Calculation of Snow Avalanche Run-out Distance, Annals of Glaciology, 4, 24-29, 1983.

Bakkehøi, S. and Norem, H.: Comparing topographical and dynamical run-out models by ideas of "Nearest Neighbour Method", 2nd Avalanche-Dynamics-Workshop in Innsbruck, Preliminary, 1993.

Bakkehøi, S. and Norem, H.: Sammenlikning av metoder for beregning av maksimal utlpsdistanse for snskred (Comparison of methods for calculation of maximum avalanche runout distance), Norwegian Geotechnical Institute, report 581200-30 (in Norwegian), 1994.

Barbolini, M. and Savi, F.: Estimate of uncertainties in avalanche hazard mapping, Annals of Glaciology, 32, 290-298, 2001.

Furdada, G. and Vilaplana, J. M.: Statistical prediction of maximum avalanche run-out distances from topographic data in the western Catalan Pyrenees, Annals of Glaciology, 26, 285-288, 1998.

Harbitz, C. B. (Ed) A survey of computational models for snow avalanche motion. Deliverable D4 of the EU project SAME, also in: Norwegian Geotechnical Institute, report no. 581220-1, http://same.grenoble.cemagref.fr/, 1998.

Harbitz, C. B., Domaas, U., and Engen, A.: Design of Snow Avalanche Deflecting Dams. Proceedings of the 9th Inter- praevent 2000 Congress, 26-30 June 2000, Villach, Austria, 1, 383-396, also in: Norwegian Geotechnical Institute, report 589000-4, 2000.

Harbitz, C. B., Harbitz, A., and Nadim, F.: On Probability Analysis in Snow Avalanche Hazard Zoning. Annals of Glaciology, 32, 290-298, also in: Norwegian Geotechnical Institute, report 20001018-1, 2001.

Irgens, F.: in review. Simplified simulation model of snow avalanches and landslides, submitted to Journal of Glaciology.

Jóhannesson, T.: Icelandic avalanche runout models compared with topographical models used in other countries. Proceedings of 25 Years of Snow Avalanche Research at NGI, Anniversary Conference, Voss, Norway, 12-16 May, 1998, Norwegian Geotechnical Institute, publ. 203, 1998.

Jóhannesson, T.: Run-up of two avalanches on the deflecting dams at Flateyri, nortwestern Iceland, Annals of Glaciology, 32, 350354, 2001.

Lied, K., Instanes, B., Domaas, U., and Harbitz, C. B: Snow avalanche at Bleie, Ullensvang, January 1994, Proceedings of 25 Years of Snow Avalanche Research at NGI, Anniversary Conference, Voss, Norway, 12-16 May, 1998, Norwegian Geotechnical Institute, publ. 203, 1998.

Lied, K., Weiler, C., Bakkehøi, S. and Hopf, J.: Calculation methods for avalanche run-out distance for the Austrian Alps. Norwegian Geotechnical Institute, report 581240-1, 1995.

Kristensen, K., Harbitz, C. B., and Harbitz, A.: Significance of Historical Records for Avalanche Hazard Zoning in Norway. Proceedings of the International Snow Science Workshop 2000, 48 October 2000, Big Sky, Montana, USA, also in: Norwegian Geotechnical Institute, report 20001018-5, in press, 2002.

McClung, D. M., Mears, A. I., and Schaerer, P.: Extreme avalanche run-out: Data from four mountain ranges, Annals of Glaciology, 13, 180-184, 1989.

Perla R. I., Cheng, T. T., and McClung D. M.: A Two-Parameter Model of Snow-Avalanche Motion, Journal of Glaciology, 26, 94, 197-207, 1980.

Tai, Y. C., Noelle, S., Gray, J. M. N. T., and Hutter, K.: An accurate shock-capturing finite-difference method to solve the SavageHutter equations in avalanche dynamics, Annals of Glaciology, 32, 350-354, 2001. 